\section{La hilarante búsqueda del Paraíso en casa en el tiempo suspendido}

\section{Tatiana Suárez-Turriza}

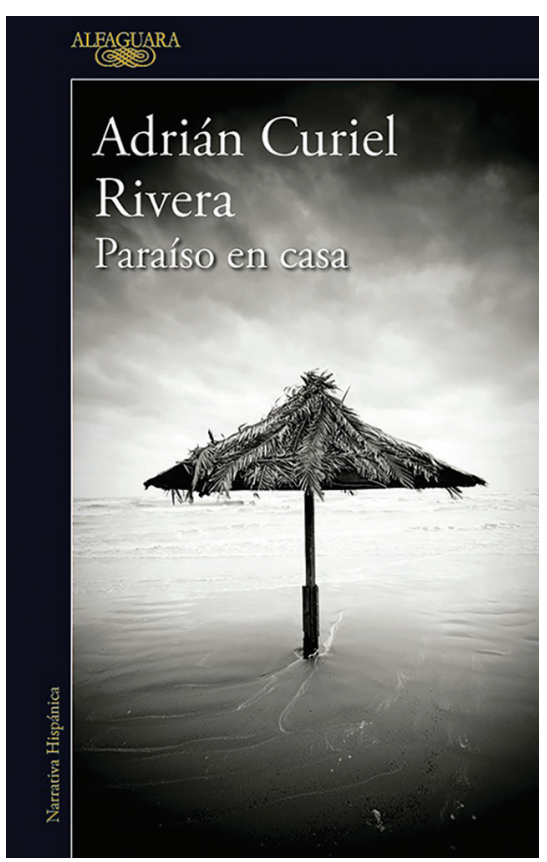

Adrián Curiel Rivera, Paraíso en casa, ISBN: 9786073162562 , Ciudad de México, Alfaguara, 2018, 326 pp. on su novela Blanco Trópico (2003), Adrián Curiel inició un camino para desentrañar - acaso expurgar-, mediante la ficción y el humor, el paradójico y sofocante ámbito académico y literario. Su novela Paraíso en casa (2018) representa un nuevo trayecto en ese sendero de exploración ficcional de los espinosos terrenos del mundo intelectual, editorial y artístico, contextualizado ahora en la tórrida región yucateca.

Paraíso en casa narra dos historias paralelas. La principal es la de Regino Félix Félix, un 'uach' (término con el que se designa en el sureste al 'chilango') cincuentón, pudiente empresario que huye con su familia a Mérida para salvarse de la 'violencia' de la capital, harto de los asaltos. Al año y medio de radicar en la Ciudad Blanca, lo abandonan su mujer y sus hijos, cansados, entre otras circunstancias peninsulares, del clima extremo, de no "poder pensar algo con el cerebro cociéndoseles a más de cuarenta grados centígrados día y noche, a sol y sombra" (24). ${ }^{1}$ Ante su repentino desamparo, Regino, a quien siempre lo había "carcomido el gusanillo del arte literario" y que pese a su "cabeza ingenieril, no era por completo inculto en materia literaria", decide, para "reivindicar su orgullo y hombría” y "vengarse de algún modo de la realidad", escribir una "novela de amor perdido y denuncia social": Paraíso en casa.

Con ese propósito, se inscribe al Taller Literario Elenita Poniatowska Nueva Época, presidido por la seductora Lula Azero. A las reuniones asisten, además de Regino, Felipe, el cronista de Mérida, quien tiene como proyecto redactar una obra laudatoria — como es de esperarse - sobre la ciudad, intitulada Amar a Mérida; y Tony Motolinía, joven poeta, estudiante de Letras, que escribe su estrafalario Jotamario como expresión reivindicadora de su condición homosexual. El taller se convierte en el escenario inquisitorial en el que el protagonista desarrolla, contra toda crítica y desaliento, la "obra de su vida". En este lugar, Regino enfrenta todo lo que implica la catarsis creativa: la puesta en escena de sus miedos, frustraciones, perversiones y oscuros instintos, que lo conducen inexorablemente a la epifanía; la "revelación, iluminación, de la realidad interior, de la propia condición, de la mediocridad, la mezquindad".

1 Todas las citas pertenecientes a Paraíso en casa corresponden a Curiel Rivera, 2018, por lo cual sólo se anota el número de página. 
Adrián Curiel parece dialogar lúdicamente con la noción de epifanía que desarrolló James Joyce en sus relatos, también presente en la narrativa de Proust y, claro, en Borges. Ésta suele presentarse como una visión simbólica que revela dolorosamente a los personajes su propia miseria. En Paraíso en casa, sin embargo, tal revelación forma parte de la sátira respecto del quehacer artístico e intelectual. Si en la magistral En busca del tiempo perdido un vulgar trozo de pan, una magdalena remojada en un té se convierte en el motivo, el símbolo que detona la epifanía (en este caso mediante la memoria), en Paraíso en casa es una pizza pastorera, que Regino se zampa completita en el restaurante Los Trompos de City Center, la que suscita el descubrimiento doloroso - por la fuerte indigestión que le provoca - de su propia desdicha, de la fatalidad que rige su vida: "decidió retirar mil dólares... lo asaltaron. Decidió mudarse a Mérida... lo abandonaron... Decidió escribir una novela de amor traicionado y denuncia social... acabó inscribiéndose en el Taller Literario Elenita Poniatowska Nueva Época” (37). A su particular teoría del caos, Regino la bautiza como el "principio de la pizza pastorera" (37).

La segunda caja china del libro, la novela dentro de la novela que se urde ante nuestra lectura, es Paraíso en casa, de Regino Félix. Esta obra narra, entre otras historias, las aventuras amorosas y adúlteras de Humberto (Beto Bala), líder de la Sociedad de los Caballeros de la Fe Perdida, una suerte de patético, esperpéntico grupo de autodefensa conformado por 'acaudalados' y fatuos ciudadanos de Traslasierra, que pretenden "mantener a raya la polio de la delincuencia" en su ciudad, "aunque el resto del país se esté hundiendo" (93). Esa agrupación — también llamada La Legión, a sugerencia del 'mantecoso' cronista yucateco - es trasunto paródico de la Sociedad del Escudo, formada por Yukio Mishima, escritor admirado por Humberto. Emulando al autor japonés, Beto Bala intenta, por medio de su sociedad de hombres armados, restablecer los 'valores tradicionales' que se han perdido; con ese propósito también escribe - más bien, contrata a 'un negro' para que le escribaun libro que titula Paraíso en casa: "una reflexión desde la filosofía moral, insoslayable en los tiempos que corren. Una reivindicación de la familia y la sociedad tradicionales, incluso por medio del uso legítimo de la fuerza" (63), obra que los protagonistas de la novela de Félix encuentran en la estantería del supermercado de otro Paraíso en casa, de Julián Zavala Dilinger, personaje de Blanco Trópico, de Adrián Curiel. Irónicamente, esta obra, el Paraíso en casa de Humberto, es el pretexto para la aventura adúltera que desencadena la trama de Paraíso en casa, de Regino Félix. 
Si lo que aquí tenemos es una 'novela de taller', como la ha definido en tono de broma su propio autor -Adrián Curiel, posible alter ego de Regino Félix-, lo es porque se erige como espacio del ejercicio creativo y expone deliberadamente el artificio mediante el filtro del humor. El complejo andamio metaficcional del relato dentro del relato, más aún, del relato que se construye a partir del relato —en un virtuoso juego metadiscursivo-, nos involucra, como es obvio, en una dinámica lúdica de confusión de planos, entre realidad y ficción, palabra (literaria) y acción. Se trata de una entreverada y cóncava arquitectura cimentada en pulidos registros del lenguaje, de páginas como espejos en los que se confunden y sobreponen las identidades: los autores, los narradores, son personajes; los personajes son autores (narradores); los lectores y críticos son (somos) también, en cierto sentido, creadores de la(s) novela(s).

Desde el epígrafe, tomado del escritor Yukio Mishima, se expone uno de los posibles hilos de Ariadna que nos permiten relacionar las cajas chinas que componen esta edificación novelesca: la reflexión sobre el lenguaje literario como producto corrosivo de la realidad. El humor constituye el recurso que acentúa el efecto incisivo de las palabras. La novela de Adrián Curiel es profusa, hilarante y mordaz. Como bien se advierte en la contraportada del libro, el autor no deja títere con cabeza: instituciones, clases sociales (media, burguesa, marginal), familia, paternidad, académicos, gobierno, intelectuales, literatos, críticos, incluso se atreve a meterse — vaya temeridadcon la 'casta divina' yucateca. A todos somete al efecto deformante, y por ello revelador, de su humor acre, fino, no sin asomos de benevolente nostalgia.

Una escena, entre otras, resume de manera simbólica, como suerte de puesta en abismo, la concepción de la literatura, del arte, como instrumento corrosivo de la realidad posmoderna; me refiero a la anécdota de la visita de Regino a la exposición de las esculturas de Anish Kapoor en el MUAC, cuando éste "retorna hacia unos simpáticos monolitos especulares que rinden homenaje - acaso involuntario- a los vitrales esperpénticos de Valle Inclán en el Callejón del Gato de Madrid [...] Ante su reflejo deformante, se visualiza a sí mismo como un aburrido señor pambazo de camisa blanca y saco y al apartarse de esas engañosas lunas bruñidas [se pregunta] ino se trata de una propuesta que no nace vieja sino muerta? ¿No es así mismo cierto que la inocencia de la juventud es precisamente lo que permite el reciclaje de añejas fórmulas expresivas en otras que parecen novedosas?" (194-195).

Paraíso en casa puede definirse como una novela pastiche. Pero no en el sentido despectivo con que el 'mantecoso' cronista califica 
la obra de Regino Félix, sino de acuerdo con la conceptualización de Gerard Genette (1989), es decir, se trata de un texto que de manera deliberada y hábil imita diversos estilos y géneros con fines lúdicos, paródicos o satíricos: novela rosa, novela del narco, crónica; pero que también expone sus deudas con la tradición literaria. No parece gratuita, entonces, la alusión a Valle Inclán, con relación al arte vanguardista de Kapoor. En la novela pueden percibirse, entre otras muchas "añejas fórmulas expresivas", destellos de las Luces de bohemia que el español publicó a principios del siglo XX. Como en esta obra, en Paraíso en casa la visión esperpéntica involucra la meditación sobre el papel del arte, del artista, del escritor, en un contexto enajenante. Con Valle Inclán, la caricatura, la sátira, se instauran como una fórmula expresiva ligada a la modernidad; nace de la conciencia de los límites de la propia escritura como expresión, metáfora o representación del mundo. En su expurgación creativa, el personaje de Regino se enfrenta al reconocimiento del vacío y absurdo cotidianos: "La misma nadería hueca, retórica y demagógica de siempre, mientras en el país y el mundo entero aumentan los feminicidios" (196).

La sociedad posmoderna que expone esta novela de Curiel corresponde al mundo líquido acuñado por Bauman. El narrador sugiere desde las primeras páginas de la obra, al referirse a la actitud pesimista/egoísta de Regino ante el abandono, estas correspondencias con los planteamientos del sociólogo: "pese a la actual desazón que lo atenaza, Regino no está dispuesto a claudicar. No piensa volver a Ítaca (metáfora del hogar/paraíso perdido) [...] Si Odiseo hubiera nacido en estos tiempos, se habría dado cuenta de la ridiculez romántica de su empeño, en un mundo líquido donde nada perdura, donde las personas y las casas son intercambiables y desechables. Para qué volver a Ítaca si se puede comprar otra Ítaca más o menos de las mismas características y hasta más barata” (25).

La paradoja vital de Regino Félix consiste en un desgarramiento entre su individualismo exacerbado (ese egoísmo que le espeta Nallely, su exmujer), su deseo de libertad y la añoranza continua de la solidez del matrimonio perdido. Ni en sus fantasías eróticas más banales deja de expresar un deseo irreprimible por casarse de nuevo: "Con esa morenita se casaría cinco veces", "Con esa rubia: que su vida fuera otra, que cogieran pletóricos de felicidad y de placer" (192). Regino encaja en la definición del individuo líquido moderno de Bauman (2005: 8-9): un hombre individualista, ávido y desesperado por entablar relaciones para tener una ilusoria seguridad o solidez, porque se sabe fácilmente descartable; su noción de matrimonio es la de un amor líquido en el que el 'para siempre' es impensable, motivo de angustia y tensión. 
Paraíso en casa constituye una historia de búsqueda y dolorosa aceptación de la libertad por medio del arte, la literatura, la creación, en medio de la orfandad en la que nos sume la 'vida líquida', signada por la violencia (o por las consecuencias devastadoras de nuestra falta de consciencia ecológica), con su continua sucesión de nuevos comienzos, con breves e indoloros finales (Bauman, 2006: 10). Tanto en fondo como en forma, esta obra exhibe la temeridad de asumir y ejercer la autonomía mediante la palabra escrita. Leerla nos recuerda que la literatura debe ser un paraíso de libertad, aún en el confinamiento de la intimidad, de la propia casa. Mediante su arquitectura impecable, cuidadoso artificio lingüístico y humor mordaz, esta novela expresa la nostalgia por la creación como un acto sin ataduras morales o sociales, sin urgencias académicas o pretensiones editoriales; la nostalgia de una escritura por placer, que busca el placer, y también ipor qué no? la salvación del desamor, del tedio, de la soledad o del miedo.

\section{REFERENCIAS}

Bauman, Zygmunt (2005), Amor líquido, México, FCE.

Bauman, Zygmunt (2006), Vida líquida, Madrid, Paidós.

Curiel Rivera, Adrián (2018), Paraíso en casa, México, Alfaguara.

Genette, Gerard (1989), "Pastiche ficticio", en Palimpsestos, Madrid, Taurus, pp. 118-125.

Tatiana Suárez TurRiza. Licenciada en Lengua y Literatura Hispánica y Maestra en Literatura Mexicana por la Universidad Veracruzana (UV) México; Maestra y Doctora en Literatura Hispánica por el Centro de Estudios Lingüísticos y Literarios de El Colegio de México (Colmex), México. Sus líneas de investigación son: literatura mexicana del siglo XIX, vanguardias hispánicas, ecdótica y didáctica de la literatura. Sobre estos temas ha publicado diversos artículos en revistas académicas indexadas. Ha publicado los libros: Los yucatecos pintados por sí mismos. Estudio y edición de los primeros artículos de costumbres de Yucatán en el siglo XIX (UNAM, 2017); y la edición crítica (estudio, notas, cronología) de los Cuentos románticos de Justo Sierra (UNAM/ Pengüin Random House, 2019). Es profesora de tiempo completo de la Universidad Pedagógica Nacional, sede Campeche. Es miembro del Sistema Nacional de Investigadores, Nivel I. 